\title{
GUERREIRO RAMOS INTERPELA A UNESCO: ciências sociais, militância e antirracismo
}

\author{
Marcos Chor Maio*
}

\begin{abstract}
Este artigo analisa as críticas de Guerreiro Ramos à proposta da Unesco de patrocinar uma série de pesquisas sobre as relações raciais no Brasil no início dos anos 1950. O estudo analisa os trabalhos de Guerreiro Ramos entre 1946 e 1950, considerando suas críticas à tradição de estudos afro-brasileiros, suas abordagens acerca do preconceito de cor sob o prisma das intersecções entre sociologia e psicologia social e as reflexões do cientista social sobre a necessidade de formação de uma intelligentsia negra com o objetivo de combater a discriminação racial no país. Apesar da proposta de Guerreiro Ramos de um Congresso Internacional sobre Raças, ao invés de uma pesquisa acadêmica, não ter vingado, ela gerou um efeito não previsto com a ampliação e diversificação dos estudos da Unesco. Concorreu para tal mudança a existência de um cenário em aberto que foi sendo construído a partir da atuação autônoma de uma rede transatlântica de cientistas sociais progressistas, com experiências diversas de ensino e/ou pesquisa no Brasil e sensível às demandas apresentadas no $1^{\circ}$. Congresso do Negro Brasileiro, patrocinado pelo Teatro Experimental do Negro (TEN).

Palavras-chave: Racismo. Teatro Experimental do Negro. Alberto Guerreiro Ramos. Pensamento Social no Brasil. Unesco. História das ciências sociais.
\end{abstract}

\section{INTRODUÇÃO}

Em agosto de 1950, o sociólogo Alberto Guerreiro Ramos submeteu uma tese intitulada "A UNESCO e as Relações de Raça" ao $1^{\circ}$. Congresso do Negro Brasileiro, promovido pelo Teatro Experimental do Negro TEN). Guerreiro propôs à Organização das Nações Unidas para a Ciência, Cultura e Educação (UNESCO) a realização de um encontro com o objetivo de discutir a adoção de medidas de combate ao racismo. Tratava-se de uma proposta que buscava inserir a intelectualidade negra brasileira no debate internacional sobre formas de enfrentamento da discriminação racial, examinando as atividades desenvolvidas pelo TEN, na interface entre a sociologia e a psicologia social, tendo em vista valorizar a subjetividade de negros e mulatos (Guerreiro Ramos, 1982).

Dentre as ações do movimento negro a partir da redemocratização de 1945, o Congresso do TEN representou mais um esforço

* Doutor em Ciência Política. Professor do Programa de Pós-graduação em História das Ciências e da Saúde da Casa de Oswaldo Cruz, PPGHCS/COC/Fiocruz. Pesquisador $\mathrm{CNPq} 1 \mathrm{~B}$.

Av. Brasil 4036, sala 403. Manguinhos. Cep: 21040361. Rio de Janeiro - Rio de Janeiro - Brasil. maio@fiocruz.br na construção de uma aliança política antirracista, reunindo militantes e intelectuais negros e brancos, em contexto de denúncias de práticas racistas no Brasil, como foi o caso, de grande repercussão à época, da proibição da antropóloga e bailarina negra norte-americana Katherine Dunham de se hospedar no Hotel Esplanada em São Paulo. Esse episódio foi um catalisador que levou o deputado federal Afonso Arinos (UDN-DF) a propor, em meados do ano de 1950, um projeto de lei que criminalizasse atos racistas (Grin e Maio, 2013).

No plano internacional, a UNESCO formulou uma agenda educacional contra o racismo, ainda sob o impacto do genocídio nazista, do processo de descolonização do Terceiro Mundo e dos primeiros passos da Guerra Fria. Em junho de 1950, a $5^{\text {a }}$. Conferência Geral da UNESCO aprovou a realização de um conjunto de pesquisas sobre as relações raciais no Brasil. O país era visto como um laboratório que atestaria cientificamente o alegado caráter singular e harmonioso das interações raciais, em contraponto às experiências dos EUA e África do Sul (Maio, 1997). ${ }^{1}$

${ }^{1}$ Do Projeto UNESCO participaram: Charles Wagley, Roger 
Desde o período de gestação do programa de estudos, a liderança do TEN buscou um novo sentido para a iniciativa da UNESCO. Guerreiro Ramos sugeriu à agência multilateral que patrocinasse um Congresso Internacional de Relações de Raça com o objetivo de definir uma agenda politicamente orientada, de intervenção social, com base na experiência do TEN, ao invés de limitar a resolução da agência a investigações acadêmicas.

Apesar de a proposta de Guerreiro Ramos não ter vingado, ela gerou um efeito não previsto, com a ampliação e diversificação do plano de estudos da UNESCO. Concorreu para tais mudanças a existência de um cenário em aberto, que foi sendo construído a partir da atuação autônoma de uma rede transatlântica de cientistas sociais progressistas, com experiências diversas de ensino e (ou) pesquisa no Brasil e sensível às demandas do TEN apresentadas no $1^{\circ}$ Congresso do Negro Brasileiro (Maio, 1999).

Inicialmente, examino as reflexões de Guerreiro Ramos sobre o "problema do negro" entre 1946 e 1950. Em seguida, abordo sua militância no TEN, as críticas aos "estudos afro -brasileiros" e as reflexões sobre as intersecções entre sociologia e psicologia social. Finalmente, detenho-me na análise do $1^{\circ}$ Congresso do Negro Brasileiro, as interpelações de Guer옹 reiro Ramos à UNESCO e os desdobramentos d do evento.

\section{DA "FRAUDE CONTRA O NEGRO"} ÀS POLÍTICAS SOCIAIS DE COMBATE AO RACISMO "problema do negro" ocorre em meio à reorga-

Bastide, Virginia Leone Bicudo, Luiz de Aguiar Costa Pinto, Oracy Nogueira, Aniela Ginsberg, Florestan Fernandes,

Thales de Azevedo, René Ribeiro, Edson Carneiro, Marvin

Harris, entre outros. Eles desenvolveram pesquisas no Rio

de Janeiro, São Paulo, Pernambuco e Bahia, em áreas tra-

dicionais e modernas, gerando um novo, amplo e diversi-

ficado quadro interpretativo das relações raciais no Brasil. nização da sociedade civil após o fim do Estado Novo, da $2^{a}$. Guerra Mundial e da emergência da discussão sobre o racismo no Brasil durante a Assembleia Nacional Constituinte de 1946. O senador Hamilton Nogueira (UDN-DF) denuncia práticas racistas, como a proibição do ingresso de negros na Escola Naval, na Aeronáutica, no Itamaraty, e a restrição à entrada no Brasil de imigrantes judeus sobreviventes do genocídio nazista. ${ }^{2}$ Propõe tipificação do racismo com uma emenda ao artigo 159 do projeto de constituição que visava à inclusão da expressão "sem distinção de raça ou cor" ao enunciado inicial: "todos os brasileiros são iguais perante a lei”. A iniciativa encontravase de acordo com os princípios aprovados pela Convenção do Negro Brasileiro de 1945 (Grin e Maio, 2013; Nascimento, 1982).

Nesse contexto, Guerreiro Ramos concedeu entrevista ao Diário Trabalhista, periódico que manteve uma coluna destinada aos "problemas e aspirações” da população negra, entre 1946 e 1948, sob a direção de Abdias Nascimento. A coluna contou com a colaboração de diversos intelectuais (Sebastião Rodrigues Alves, Ironides Rodrigues, Aguinaldo Camargo entre outros), pertencentes ao movimento negro, e cientistas sociais como Arthur Ramos e Thales de Azevedo (Guimarães; Macedo, 2008).

Guerreiro abordou o "problema do negro" a partir das seguintes variáveis: o preconceito racial, o preconceito de classe e os condicionantes culturais e psicológicos que incidem sobre as relações raciais. No primeiro caso, cita autores da denominada Escola Sociológica de Chicago (Robert Park, E. B. Reuter e Franklin Frazier), da antropologia boasiana (Melville Herskovits, Ruth Benedict) e cientistas sociais brasileiros (Gilberto Freyre, Arthur Ramos) para demonstrar a ausência de bases científicas para a existência do racismo. No entanto, assinala que a discriminação racial persiste como instrumento de dominação política e social dos brancos. O sociólogo sublinha

${ }^{2}$ Discurso de Hamilton Nogueira na $25^{\mathrm{a}}$. Sessão da Assembleia Nacional Constituinte, 14.03.1946, p. 408-414. 
a tradicional comparação entre a experiência norte-americana da segregação, do conflito racial, e o caso brasileiro, que é "mais disfarçado e o negro sofre uma discriminação menos ostensiva. Entre nós, o preconceito racial perde em importância para outros dois aspectos da questão: o preconceito de classe e a incompatibilidade de dois mundos mentais distintos" (Nascimento, 1946, p. 6).

Quanto ao preconceito de classe, Guerreiro Ramos observa que o processo de ascensão social dos não brancos conduz, frequentemente, à percepção da ausência da distinção entre classe e cor. Ele comunga das ideias preconizadas pelo sociólogo Donald Pierson sobre as relações raciais no Brasil (Pierson, 1945), atribuindo à classe social a chave explicativa do preconceito de cor. Em suas palavras: "o homem de cor no Brasil é uma criatura em ascensão econômica [...]. Assim, muitos dos seus fracassos são atribuídos ao preconceito racial quando, muitas vezes, devem ser atribuídos aos de classe. Na Bahia corre um dito, de que branco pobre é negro e negro rico é branco, o que dá, em forma pitoresca, alguma medida desta luta de classes" (idem, 1946, p. 6).

Guerreiro ainda discorre sobre as resistências psicoculturais às mudanças sociais como uma importante dimensão do que denomina "a incompatibilidade de dois mundos mentais distintos." Haveria, no domínio das camadas populares, uma "cultura negra no Brasil, com seu sincretismo religioso, seus hábitos alimentares, sua medicina de 'folk', sua arte e sua moral." (idem, p. 6) Contudo, a cultura afro-brasileira representaria o passado, as sobrevivências advindas do tempo da escravidão. Esse mundo pautado pela tradição encontra-se em crescente tensão com o processo de modernização do país. Guerreiro entende que "o 'peneiramento' social do homem de cor brasileiro é realizado mais em termos de cultura e de status econômico do que em termos de raça." (idem, p. 6). Desse modo, com a mobilidade socioeconômica e a mudança de hábitos, costumes, atitudes, o negro poderia se inserir no mundo dos brancos.
Para a realização de tal projeto de incorporação social, Guerreiro se opunha à proposta de organização política dos negros como forma de combater o preconceito de cor, destoando dos posicionamentos de Abdias Nascimento e demais militantes. O movimento negro devia limitar seu raio de ação às atividades culturais, recreativas e filantrópicas. A solução para o "problema do negro" passaria por um processo de "planificação da economia nacional que venha elevar o nível econômico das classes pobres [...] sem distinção de cor" (idem, p. 6).3 Tema caro a Guerreiro, a proposta de planificação revela inspiração mannheimiana, com a valorização do papel do Estado como instrumento de controle racional da economia capitalista, acompanhada pela distribuição da riqueza. Ela implica ainda a participação de uma intelligentsia que estaria capacitada a definir os modelos de intervenção social apropriados. Políticas sociais centradas nas classes populares, compostas por parcela significativa de pessoas de cor, poderiam provocar mudanças na estrutura econômica com impactos na dinâmica da ascensão social e na redução das desigualdades sociais entre brancos e negros, sem enveredar por conflitos raciais (Guerreiro Ramos, 1946; 1946a).

No calor dos debates da Constituinte de 1946, Guerreiro Ramos ponderava que "a democracia não pode, por definição, consagrar privilégios e consiste, em certo sentido, numa regulamentação do jogo da competição. Se neste jogo competitivo, se favorece a uns em detrimento de outros, há fraude. O senador Hamilton Nogueira denunciou à constituinte uma fraude contra o negro" (Nascimento, 1946, p. 6). Para se contrapor a distorções, Guerreiro Ramos sugere que o processo democrático seja "questão de engenharia social" e não somente de um regime político formal (Guerreiro Ramos, 1945). ${ }^{4}$

${ }^{3}$ A recusa de Guerreiro Ramos em atribuir importância política ao movimento negro foi alvo de críticas de Abdias Nascimento, que creditava a uma série de organizações papel central na luta contra o racismo (Nascimento, 1946, p. 6).

${ }^{4}$ Em curso ministrado no DASP sobre métodos de pesqui- 
Em julho de 1948, quando proferiu palestra intitulada "Contatos Raciais no Brasil", em homenagem ao jornalista negro norte-americano George S. Schuyler, do Pittsburgh Courier, Guerreiro retoma reflexões contidas na entrevista a Abdias Nascimento sobre o "problema do negro", que deve ser analisado a partir das variáveis: classe, região e zonas rurais e urbanas. Ressalta os aspectos psicossociais que incidem sobre o comportamento do negro, como o ressentimento dos setores subalternos em relação aos negros de classe média. Por fim, critica cientistas sociais por valorizarem as "chamadas culturas negras". Guerreiro Ramos avalia que "o homem de cor [...] considera pitorescos os traços das culturas africanas", identificando-se com a cultura da classe dominante (Guerreiro Ramos, 1948, p. 5).

Com base nessas reflexões de Guerreiro, destaco três aspectos: 1) a presença de uma estratificação social entre os próprios negros, que resulta em tensões. Em sua pesquisa, Bicudo (2010), sob a orientação do sociólogo Donald Pierson, já havia verificado que os negros de menor poder aquisitivo apresentavam atitudes de maior rejeição em relação a negros e mulatos quando comparados com os brancos. Tais atitudes de rivalidade entre os pretos e de seu convívio mais harmonioso com os brancos estariam calcadas no sentimento de inferio늘 ridade dos negros. Os brancos seriam vistos స. como mais simpáticos, suscitando maior tole\&ância dos negros e evitando a possibilidade de

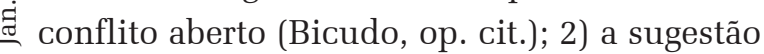
de uma abordagem na intersecção sociologia A e psicologia mediante práticas terapêuticas ci como o psicodrama, inspiradas nos ensinaa mentos do médico psiquiatra e sociólogo Jacob

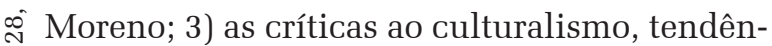

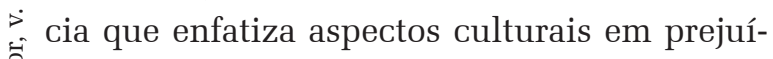
sa aplicados aos problemas de assimilação e aculturação de imigrantes, Guerreiro Ramos aplicou uma centena de - questionários para um grupo de servidores públicos, uti-

Iizando a técnica de Bogardus de distância social. Verifi-

cou-se um acentuado percentual de preconceito contra o negro e o mulato. Guerreiro assinala que " $77,35 \%$ dos pesquisados não admitiam casamento com negro e 54,71\% dos mesmos não admitiam esta relação com os mulatos" (Guerreiro Ramos, 1948a, p. 2). zo da análise da estrutura social e cujo efeito seria a dificuldade de discernir os meios que levariam os negros a ascender socialmente. Guerreiro posiciona-se contra a visão do negro como "material etnográfico", em detrimento de uma perspectiva de transformação da condição social marginalizada da população de cor (Guerreiro Ramos, 1950a).

\section{A CRÍTICA AOS ESTUDOS AFRO -BRASILEIROS E A AFIRMAÇÃO DA SOCIOLOGIA}

Desde o final da década de 1930, cientistas sociais, ativistas negros e militantes comunistas se posicionaram criticamente em relação aos estudos afro-brasileiros. O jornalista, escritor e membro do Centro Negro de Cultura Social, Fernando Góes, publicou, em 1939, um artigo na revista Seiva, vinculada à seção baiana do Partido Comunista Brasileiro (PCB), no qual critica as investigações centradas nos aspectos religiosos, culturais, associados à tradição afro-brasileira (rituais, músicas, danças). A seu ver, "não houve, ainda, aquele que se abonasse a estudar a vida, única e simplesmente a vida do negro brasileiro moderno, o negro da cidade, com todas as suas dolorosas e intermináveis tragédias, derivadas não só de uma situação econômica mais do que lamentável, como também de sua posição moral junto ao homem branco do Brasil” (Góes, 1939).

Seguindo caminho semelhante, no artigo "Para onde vai a afrologia?" (1940), publicado no Clarim d'Alvorada, jornal da imprensa negra, de Luiz Bastos (pseudônimo de Leôncio Basbaum), militante e intelectual do PCB, ele faz uma critica aos "afrologistas", por se limitarem à descrição dos rituais religiosos e estudos de antropologia física do negro brasileiro. Conforme sua perspectiva, "não basta transcrever as palavras aparentemente sem nexo dos cantos dos candomblés, mas, ao contrário, investigar o seu significado social, que tem, evidentemente, um fundo maior de opressão racial e 
econômico.” O autor contrapõe a ênfase nos estudos etnográficos sobre o negro à visada sociológica, que aponta as assimetrias: "cinquenta e dois anos depois da sua emancipação o negro não passou ainda do miserável habitante das favelas, do trabalhador braçal, do soldado raso e do fetichismo. Por quê? Porque ainda existe o preconceito do branco contra o negro, fundamente impregnado em todas as camadas mais ou menos pigmentadas do Brasil." Alerta ainda os "afrologistas" que só com o reconhecimento da questão racial no Brasil poderiam ser resolvidos os problemas socioeconômicos dos negros (Bastos, 1940). ${ }^{5}$

No início dos anos 1940, o historiador Sergio Buarque de Holanda, em Negros e Brancos, critica os estudos afro-brasileiros representados pelos trabalhos de Arthur Ramos. Ao privilegiar a influência cultural africana sobre a sociedade brasileira, eles acabam por realçar "o lado pitoresco, anedótico, folclórico, em outras palavras o aspecto exótico do africanismo" (Holanda, 1978, ênfase do autor). Com isso, eles não atentam para o aspecto problemático da condição do negro no Brasil, que sofre sutil preconceito de cor, é vítima das imprecisões dos censos demográficos e da ideologia do branqueamento e é constantemente visto como estrangeiro em sua própria terra. Dessa forma, as limitações dos estudos afro-brasileiros advêm da crença de que o negro não é problema, e sim "espetáculo" (idem, p. 12). Uma visada estereotipada do negro contribuiria para uma perspectiva racista do mundo.

Afinado com Holanda, Roger Bastide constata o reduzido número de estudos sociológicos no Brasil. Bastide propõe pesquisas com base nos dados do censo de 1940 para aferir "a situação econômico-social do negro, a distribuição dos homens de cor através das profissões e, por conseguinte, as relações entre raça e classe. [...] Poderemos obter ainda dados relacionados com a ecologia, a distribuição das raças através de todo o país, num Estado através das várias

${ }^{5}$ Originalmente, o artigo foi publicado na revista Seiva, ano1, n. 4, 13/05/ 1939. regiões, num município através das zonas rurais e urbanas [...]" (Bastide, 1945). Desse modo, os estudos sociológicos de natureza quantitativa permitiriam o avanço do conhecimento empírico sobre as diferenças sociorraciais.

Guerreiro Ramos se posiciona ao lado dos críticos dos estudos afro-brasileiros que apresentavam o negro como "peça de museu", implicando o abandono do caráter prático, político, das soluções dos problemas vivenciados pelos negros. Assim, as investigações de caráter histórico, folclórico ou antropológico, apesar de seu valor documental, partiram do princípio de que o problema do negro foi resolvido com a Abolição e que caberia apenas pesquisar as "sobrevivências africanas", em vez de oferecer condições para que o negro pudesse incorporar-se à modernidade (Guerreiro Ramos, 1950a, p. 1-2). ${ }^{6}$

Com o ingresso de Guerreiro Ramos no TEN, sua perspectiva sobre a questão racial sofre uma inflexão: ao lado da adoção de políticas de Estado, ele passa a destacar iniciativas de organizações da sociedade civil voltadas para a promoção da instrução básica e a inserção do negro no mercado de trabalho. Essa frente de ação, centrada na modificação das estruturas socioeconômicas, devia estar conjugada à outra que, enfocando a dimensão subjetiva da mudança, pretendia agir sobre a mentalidade da população negra, na remodelação de hábitos, atitudes e comportamentos. Na perspectiva de Guerreiro, o processo de "reeducação" das massas de cor seria acompanhado das transformações da situação sociocultural do país (Guerreiro Ramos, 1950, p. 37).

Ao diversificar o leque de atores envolvidos no processo de mudança da situação racial brasileira, acrescentando à ação governamental a participação da sociedade civil, o protagonismo do TEN encontra-se no projeto

${ }^{6}$ No livro O Negro no Rio de Janeiro: relações de raças numa sociedade em mudança (1953), de autoria do sociólogo Luiz de Aguiar Costa Pinto, fica patente que sua crítica ao culturalismo, na vertente dos estudos afro-brasileiros, sofre evidente ascendência das reflexões de Guerreiro Ramos sobre o tema no contexto da produção sociológica e política do então militante do TEN. 
de uma vanguarda munida de uma cultura técnico-científica, ou, em suas palavras, de "senso sociológico” (Nascimento, 1950, p. 11).

\section{ENTRE A SOCIOLOGIA E A PSICO- LOGIA SOCIAL: Guerreiro Ramos no Teatro Experimental do Negro}

Criado em outubro de 1944 no Rio de Janeiro, ao apagar das luzes do Estado Novo, sob a liderança do jornalista e teatrólogo Abdias Nascimento, a princípio, o TEN constituiu-se como movimento cultural, uma resposta aos limites impostos aos negros pelo preconceito racial. Dos ensaios e peças apoiados numa rede de intelectuais, atores, políticos, jornalistas, o TEN foi se politizando com a democratização do país no pós-2 ${ }^{\text {a }}$ Guerra Mundial (2 ${ }^{\text {a }}$ Guerra Mundial) e o avanço da luta contra o racismo (Muller, 1988, p. 13-15).

Nos primórdios do envolvimento com o TEN, Guerreiro Ramos assume três desafios: 1) um projeto de valorização da subjetividade de negros e mulatos, assolada pelos recalques provocados pela escravidão e pela exclusão do processo de modernização capitalista, por meio do teatro, do psicodrama, do sociodrama; 2) a formação de uma intelligentzia negra que, ao lado das elites brancas, superasse o desเص compasso entre a condição formal de cidadão livre, adquirida pelo negro após a Abolição, e sua adversa situação econômica e sociocultu(ู) ral, ainda presente sessenta anos depois; 3) um क् conjunto de iniciativas de profissionalização $\hat{\wedge}$ de mulatos e negros.

Em 1949, Guerreiro Ramos participou a da Conferência Nacional do Negro, na qual foi 汿 eleito para o comitê organizador do $1^{\circ}$ Con-

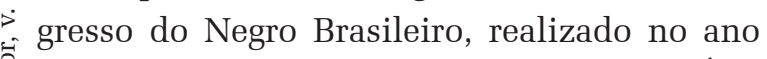
seguinte, ao lado de Abdias Nascimento e Édison Carneiro. Tornou-se diretor do Instituto Nacional do Negro (INN) órgão responsável pela promoção de cursos nas áreas de educação, cultura e formação profissional, além de promover atividades cênicas e dinâmicas de grupo de caráter psicoterapêutico (Guerreiro Ramos, 1949, p. 6). Coordenou um seminário de Grupoterapia para os alunos do TEN, no intuito de formar pessoal habilitado para "atuar nos morros, terreiros e nas associações de gente de cor" (Quilombo, 1949, n. 3, p.11).

Nos seminários de Grupoterapia, o sociólogo analisou o caráter coercitivo, e mesmo trágico, a seu ver, da socialização do indivíduo na era moderna, concebida como processo de integração à ordem social que, ao inculcar-lhe modos padronizados, sancionados pelo grupo, de compreensão, comportamento e desejo, acaba por comprometer sua autonomia, autenticidade e espontaneidade. No intuito de pensar as cisões que estariam presentes na relação entre indivíduo e sociedade, além do fundador do Grupoterapia, Jacob Moreno, Guerreiro mobiliza autores como Robert Owen, Charles Fourier, Émile Durkheim e Erich Fromm (Guerreiro Ramos, 1949; 1950).

Para o sociólogo, a Grupoterapia oferecia, por meio do teatro, a oportunidade para o negro enfrentar seus temores e ressentimentos, expurgando de sua personalidade os estereótipos raciais e as visões autodepreciativas incorporadas desde a infância. Tratava-se da transposição para o palco de situações de preconceito e conflito concretas, tais como eram vivenciadas pelo indivíduo. ${ }^{7} \mathrm{O}$ depoimento de Ruth de Souza, atriz do TEN desde 1945 e que atuara em diversas peças patrocinadas pela organização, permite compreender a proposta psicossocial levada a cabo por Guerreiro Ramos. A experiência de infância da atriz, que viera de uma cidade do interior para o Rio de Janeiro, foi objeto de dramatização no INN, conforme seu relato:

${ }^{7}$ Um dos temas de encenação no INN foram as relações, permeadas de tensão, entre patrões e empregadas domésticas (Guerreiro Ramos, 1995, p. 173). Em carta a Florestan Fernandes, Guerreiro informa que iniciaria, possivelmente em novembro de 1950 , a dramatização do conteúdo dos sonhos de indivíduos negros (Carta de Guerreiro Ramos a Florestan Fernandes, s./d., Fundo Florestan Fernandes, 02.09.1591). Nesse caso, chamara-lhe a atenção o trabalho de Roger Bastide apresentado no I Congresso do Negro Brasileiro, cuja análise dos sonhos de indivíduos negros revelava sua identificação com os padrões estéticos do branco (Guerreiro Ramos, 1950b, p. 1 e 3). 
Minha mãe era do interior. Ela era a Dona Alaíde, dona de um pedaço de terra, uma senhora respeitada [...]. E quando nós viemos para o Rio, ela tornou-se lavadeira. Nós éramos a filha da lavadeira, Alaíde a lavadeira, eu me lembro disso. [...] Depois eu comecei a chorar [durante a experiência grupoterápica sob a orientação de Guerreiro Ramos] porque foi quando eu descobri que eu era pobre. Quando eu cheguei no Rio de Janeiro, tornei-me negra, eu não sabia que eu era negra. Sabe, quando criança não presta atenção? E eu me lembro disso, que a descoberta de ser negra foi aqui no Rio de Janeiro, a descoberta das diferenças de classes, que eu não entendia. Fui crescendo e não entendendo muito bem porque é que [...] você me trata diferente se eu sou gente igual a você?

A encenação de uma situação em que fora alvo de preconceito, como a "filha da lavadeira”, na casa dos patrões da mãe, possibilitou a Ruth de Souza uma nova compreensão sobre as causas do episódio, associadas à condição de menina negra e pobre e à perda de status social da família no contexto urbano. Além de servir de base para o entendimento das relações sociais que marcavam a vida de negros e mulatos, a dramatização produziria um efeito psicológico libertador, restituindo-lhes a autoestima e a confiança nas próprias capacidades criadoras (Guerreiro Ramos, 1950c, p. 6; 1950d, p. 9). ${ }^{8}$

Além do Seminário de Grupoterapia, o INN desenvolvia atividades educacionais e profissionais. Em carta a Florestan Fernandes, de janeiro de 1950, Guerreiro compartilha com o sociólogo o projeto de "instalar em Caxias, a Meca dos Negros do Estado do Rio de Janeiro, uma Instituição de Orientação Profissional. Por enquanto vai começar com uma escola primária. Mas penso em fazer oficinas de alfaiataria, tipografia, marcenaria, eletricidade e uma escola de domésticas". ${ }^{9}$

${ }^{8}$ Entrevista de Ruth de Souza concedida ao autor em 30/10/1996.

9 Carta de Guerreiro Ramos a Florestan Fernandes, 4/1/1950, p. 2, Fundo Florestan Fernandes, 02.09.0590. Em abril de 1950. O Quilombo, jornal do TEN, publicou nota elogiosa a respeito da disposição do engenheiro e empresário Jael de Oliveira Lima em patrocinar a construção de uma escola voltada para a formação das categorias profissionais citadas na carta de Guerreiro. A iniciativa estaria afinada à "linha da política que vem sendo executada no
No plano estritamente político, Guerreiro Ramos analisa o papel a ser desempenhado pela "elite negra" que estava sendo forjada pelo TEN. Para isso, aborda o lugar do negro na sociedade ocidental. A incorporação dos padrões culturais ocidentais pelos negros havia produzido, principalmente entre aqueles com baixo nível de instrução, comportamentos ambivalentes, que oscilavam entre a identificação com as "sobrevivências das culturas negras" e os valores próprios à sociedade moderna ocidental. Essas atitudes seriam superadas mediante o reconhecimento da contribuição dos negros à civilização ocidental. Nesse sentido, cabia à "elite negra" explorar todo o potencial da "subjetividade negra", seu papel construtivo e revitalizador diante das instituições culturais do Ocidente, marcadas por um processo de burocratização, de engessamento (Guerreiro Ramos, 1950, p. 41-43).

A fim de incorporar os negros à modernidade, o TEN devia "adestrar os homens de cor nos estilos de comportamento da classe média e superior" (Nascimento, 1949, p. 11). Guerreiro Ramos foi o principal responsável pelos contornos ideológicos e políticos da ação do TEN. Embora crítico contundente dos estudos antropológicos sobre o negro, que estariam voltados para a tradição, Guerreiro, no final dos anos 1940, buscou, assim como Abdias do Nascimento, interpretar o universo psicológico do negro a partir de categorias de análise da antropologia (Tylor, Frazer) e da sociologia (Lévi-Bruhl), interessadas no denominado pensamento primitivo que se encontra nos escritos do antropólogo Arthur Ramos, especialmente no livro O Negro Brasileiro (1934). Inspirado no médico e antropólogo, Guerreiro Ramos concebia a necessidade de se criarem instrumentos racionais para sobrepujar as práticas tradicionais radicadas na estrutura dos hábitos e cristalizadas em atitudes. O processo de adestramento, de disciplinarização, contribui-

Brasil pelo [TEN] e que consiste em promover a instalação em nossa sociedade de mecanismos integrativos que acelerem a elevação do nível econômico e cultural dos brasileiros de cor." (Quilombo, 1950, n.7/8, p.5). 
ria para frear, entre outras atitudes, a adesão dos negros a ideologias de esquerda, marxistas, que se alimentavam do ressentimento e buscavam capitalizar politicamente a situação de restrição de direitos que a população negra sofria nos regimes democrático-liberais (Guerreiro Ramos, 1950, p. 43). É evidente o contexto da Guerra Fria e o alerta de Guerreiro quanto às adversidades que os negros viviam nos países capitalistas. O sociólogo chega a elogiar o Presidente Harry Truman pelos avanços no terreno dos direitos civis. Guerreiro estava distante de qualquer solução de corte marxista e julgava que o papel do TEN era o de "transformar a luta de classes num processo de cooperação", de forjar uma intelligentzia, "uma elite [...] uma espiritualidade e uma missão" (Guerreiro Ramos, 1950e, p. 50).

Guerreiro utiliza o conceito de intelligentzia, de corte mannheimiano, como segmento específico da sociedade em condições de atuar como intérprete em geral da sociedade (Werneck Vianna, 1997, p. 198), em detrimento de qualquer solução do tipo "partido de negros", na medida em que "o homem de cor, entendido como homem-massa, não estaria habilitado às funções de mando, as quais, como é sabido, supõem uma longa aprendizagem” (Guerreiro Ramos, 1950, p. 38). Caberia à intelligentsia negra a elevação social e sem 놈 conflitos da "massa negra". Para isso, o $1^{\circ}$ Congresso do Negro Brasileiro foi concebido pelo

\section{$O 1^{\circ}$ CONGRESSO DO NEGRO BRA- SILEIRO E A CRÍTICA AO "PROJE- TO UNESCO"}

O $1^{\circ}$. Congresso do Negro Brasileiro, realizado no Rio de Janeiro entre 26 de agosto e 4 de setembro de 1950, por ocasião do centenário da extinção do tráfico negreiro, tinha por objetivo formar uma ampla frente antirracista. Em lugar de estudos acadêmicos, o evento privilegiaria a discussão dos "problemas práticos e atuais da vida de nossa gente de cor", buscando soluções para os desafios da ascensão social dos negros. A liderança do TEN procurava se diferenciar dos Congressos Afro-brasileiros de 1934 e 1937 (Recife e Salvador), julgados como eventos que destacavam, sobretudo, aspectos científicos e culturais sem se ater aos aspectos políticos. ${ }^{10} \mathrm{O}$ Congresso do TEN, por sua vez, segundo editorial do jornal Quilombo, seria um "congresso sociológico por excelência [com o intuito de] descobrir mecanismos que acelerem o processo de integração de pretos e brancos instalado por nossa própria evolução histórica” (Nascimento, 1950, p. 1).

O certame reuniu cientistas sociais como Roger Bastide, Darcy Ribeiro, Charles Wagley, Luiz de Aguiar Costa Pinto, intelectuais de cor, que foram os protagonistas do evento (Édison Carneiro, Guerreiro Ramos, Abdias Nascimento), ativistas negros e os parlamentares Afonso Arinos de Melo Franco e Hamilton Nogueira. Os coordenadores do encontro buscaram também o apoio de órgãos governamentais e agências internacionais (ONU, UNESCO). Atraíram ainda intelectuais e ativistas negros de diversos estados.

Em junho de 1950, durante o processo de preparação do Congresso, Guerreiro Ramos ministrou uma conferência na Escola Livre de Sociologia e Política (ELSP), a convite do sociólogo Oracy Nogueira, intitulada "O Teatro Experimental do Negro e as experiências de sociodrama", ${ }^{11}$ eixo fundamental da sociologia militante de Guerreiro. A ELSP era uma refe-

${ }^{10}$ Se o $1^{\circ}$. Congresso Afro-Brasileiro, realizado em 1934 no Recife, esteve sob a égide da visão culturalista de Gilberto Freyre, no caso do $2^{\circ}$. Congresso, promovido em Salvador, em 1937, sob a liderança de Édison Carneiro e Aydano do Couto Ferraz, há uma mudança de sentido com um visível acento político. Nas palavras de Carneiro e Ferraz, militantes do Partido Comunista Brasileiro (PCB): "O nosso intento foi o de que melhor se compreendesse a necessidade da liberdade dos cultos afro-negro-ameríndios, como a necessidade da reabilitação social do negro brasileiro." (Carneiro \& Ferraz, 1940, p. 11). O destaque adquirido pela luta política pela liberdade religiosa, a partir do II Congresso Afro-brasileiro, permite relativizar o discurso de Abdias Nascimento quando da abertura do $1^{\circ}$. Congresso do $\mathrm{Ne}$ gro Brasileiro, no qual afirma que os congressos anteriores estavam pautados por uma "preocupação estritamente acadêmica” (Nascimento, 1950, p. 1).

11 A Conferência foi patrocinada pelas cadeiras de "Métodos de Pesquisas Sociais" e "Comportamento Coletivo" do curso de bacharelado em ciências políticas e sociais de São Paulo. A Sociologia, v. 12, n. 2, p. 172. 
rência central no âmbito dos estudos sociológicos no Brasil. Além do sociólogo Donald Pierson, Oracy Nogueira tornou-se um importante divulgador dos trabalhos realizados pela Escola Sociológica de Chicago, inclusive os estudos sobre relações raciais (Maio, 2014). Guerreiro participou também da instalação, no Departamento de Sociologia da FFCL-USP, da Comissão Paulista do $1^{\circ}$. Congresso do Negro Brasileiro, presidida pelo sociólogo Roger Bastide e pelo representante do TEN em São Paulo, jornalista Geraldo Campos de Oliveira. ${ }^{12}$ Essa aliança entre cientistas sociais e ativistas negros foi responsável pela manifestação de desagravo ao ato racista que impediu, no dia 13 de julho de 1950, a bailarina e antropóloga negra norte-americana, Katherine Dunham, de se hospedar no Hotel Esplanada. O evento foi promovido pela Comissão de São Paulo do $1^{\circ}$. Congresso Nacional do Negro, do TEN e do Centro Folclórico Mario de Andrade. ${ }^{13}$

Dentre as diversas teses discutidas durante o Congresso do Negro, a de Guerreiro Ramos, como vimos, versou sobre a UNESCO e a questão racial e, particularmente, sua crítica à natureza do projeto sobre as relações raciais no Brasil. Guerreiro Ramos reconhece a importância da instituição no processo de "integração das minorias raciais nos vários países onde elas se encontram mais ou menos discriminadas". Todavia, pondera que a organização deveria centrar a luta contra o racismo em "sugestões práticas, evitando os estudos de ordem acadêmica ou meramente descritivos e que levam a uma consciência falsa do mesmo" (Guerreiro Ramos, 1982, p. 237). Ele reitera posições assumidas desde 1948, ao cri-

12 "Primeiro Congresso do Negro Brasileiro", Jornal de Notícias, 09.06.1950, p. 1. Geraldo Campos de Oliveira foi jornalista do Diário do Povo (SP), Diário Carioca (RJ), A Pátria (RJ) e do Diário de São Paulo. Foi editor do jornal Senzala, colaborador da revista Novo Horizonte e membro do Partido Socialista Brasileiro (entrevista de Geraldo Campos de Oliveira ao autor, 12/09/1995).

${ }^{13}$ Diário de Notícias, 14.07.1950, p. 2. Além de Roger Bastide e Geraldo Campos e Oliveira, participaram da solenidade os cientistas sociais Fernando de Azevedo, Alceu
Maynard, Florestan Fernandes, Oracy Nogueira e Gilda de Melo e Souza. Da parte dos intelectuais e militantes do movimento negro, estiveram presentes: José Correia Leite, Luiz Lobato, Raul Joviano do Amaral e Fernando Góes. ticar perspectivas de natureza culturalista, que desconsideravam os aspectos pragmáticos da mudança das relações sociorraciais.

Ao invés de estudos, propunha uma agenda política pautada na atuação dos intelectuais negros, a partir da experiência do TEN, com base nas seguintes iniciativas: “a) a utilização do teatro como instrumento de integração social; b) os concursos de beleza racial como processo de desrecalcamento em massa; c) as tentativas de aplicação em massa de sociatria e de grupoterapia; d) a utilização de museus e filmes como instrumentos de transformação de atitudes" (idem, p. 238).

Guerreiro sugeria que a modelação de novas atitudes e valores em face das populações discriminadas fosse adotada como política de âmbito internacional. Além da difusão dos recursos psicoterapêuticos ligados ao teatro, o sociólogo chama a atenção para os concursos de beleza promovidos pelo TEN14 como estratégia, a um só tempo, de recuperação da autoestima do negro e de contestação, no plano da cultura, dos padrões estéticos brancos dominantes. Guerreiro buscou imprimir uma orientação política ao tratamento do tema e que pudesse assegurar resultados práticos tangíveis e cujo ponto de partida fosse um congresso sobre problemas de minorias raciais, no qual a agenda do TEN viesse a se internacionalizar.

Na primeira semana de setembro de 1950, foi publicada a Declaração Final do Congresso do Negro. A tese de Guerreiro foi incluída na parte relativa às recomendações do evento, ao lado de outra sugestão que reiterava o mito da democracia racial à brasileira, ou seja, "o estudo, pela UNESCO, das tentativas bem sucedidas de solução efetiva dos problemas de relações de raças, com o objetivo de prestigiá-las e recomendá-las aos países em que tais problemas existem". ${ }^{15}$

14 Trata-se dos concursos "Rainha das Mulatas" e "Boneca de Pixe”. Ver Quilombo (n. 3, p. 12; n. 9, p. 6-7, 1949).

15 "São os problemas do negro apenas um aspecto particular do problema geral do povo brasileiro”, Diário de Notícias, 07.09.1950, p. 2. 
Os debates ocorridos no Congresso do Negro Brasileiro ecoaram entre cientistas sociais (Charles Wagley, Costa Pinto e Roger Bastide) que estavam envolvidos diretamente com o projeto da UNESCO. Em correspondência com a direção do Departamento de Ciências Sociais da UNESCO, o antropólogo Charles Wagley fez a seguinte ponderação: "[...] quanto aos estudos urbanos sobre tensão racial (ou sua inexistência), me pergunto se Salvador não seria um tanto especial e se os estudos em São Paulo e no Rio de Janeiro não demonstrariam aspectos diferentes do quadro brasileiro de relações raciais em geral. Acabo de assistir ao Congresso Nacional do Negro no Rio e alguns dos trabalhos e algumas das discussões pareciam indicar diferenças entre Rio e São Paulo.”"16

O sociólogo Costa Pinto, que participou intensamente do Congresso do TEN, julgou que a aprovação da tese de Guerreiro Ramos fortaleceria a ideia de que, em matéria de estudos raciais, "o Brasil é o campo indicado para tais investigações" (apud Abdias do Nascimento, 1982, p. 241). Em carta ao etnólogo Alfred Métraux, Chefe do Setor de Relações de Raça da Unesco, Roger Bastide, sob o impacto do Congresso do TEN ponderou que:

[...] antes que fosse muito tarde, era preciso conferir um sentido prático às reflexões teóricas, que, fazendo trabalhar em cooperação amigável os estudantes

$>{ }^{16}$ Carta de Charles Wagley a Ruy Coelho, 6/9/1950, p. 2. of Race questions \& protection of minorities. REG 323.1. Part II up to 31/VII/50 (BOX REG 145), Unesco Archives.

${ }^{17}$ Carta de Roger Bastide a Alfred Métraux, 9/9/1950. Race questions \& protection of minorities. REG 323.1. Part II up to 31/VII/50 (caixa 145), Arquivos da Unesco. Um mês J após entrar em contato com Métraux, uma carta endereçada a Orlando Barbosa e Virginia Leone Bicudo, provavelmente escrita por Oracy Nogueira, informa que "está sendo organizado, em São Paulo, por um grupo de estudiosos J e interessados, tanto brancos como de cor, entre os quais
O relato de Bastide confirma a importância atribuída à tese de Guerreiro Ramos no processo de elaboração do projeto de pesquisas da UNESCO, especialmente no caso do estudo realizado na cidade de São Paulo, com a participação de Florestan Fernandes, no início dos anos 1950.

\section{CONSIDERAÇÕES FINAIS}

A agenda do TEN, sintetizada por Guerreiro Ramos, destoava da iniciativa da UNES$\mathrm{CO}$, que patrocinou um conjunto de pesquisas sobre as relações raciais no Brasil com o objetivo de oferecer subsídios para uma ampla campanha educacional contra o racismo. As duas propostas tinham afinidades políticas, mas se diferenciavam quanto aos meios. Roger Bastide e Florestan Fernandes procuraram estabelecer fronteiras entre ciência e política: "o estudo deve ser projetado em bases científicas, mas tem uma origem e um fim que são igualmente extra-científicos" (1951, p. 3-4). Guerreiro, por sua vez, privilegiou a experiência do ativismo negro e de uma sociologia de cunho pragmático, na esteira de estudos sobre populações marginalizadas através dos seguintes temas: puericultura, mortalidade infantil, padrão de vida e pauperismo. Ele acreditava que o estudo sociológico e a ação prática deviam ser concomitantes, de tal forma que a formulação das pesquisas exigia uma clara definição de seus alvos políticos.

A tese de Guerreiro Ramos apresentada no Congresso do Negro Brasileiro está dividida em três eixos. O primeiro versa sobre a natureza do projeto de pesquisa chancelado pela UNESCO, no qual a liderança do TEN buscou se inserir o debate internacional sobre o racismo tendo em vista a criação de um fórum

o Prof. Roger Bastide e o Prof. Geraldo Campos de Oliveira, uma comissão para estudar os problemas que afetam a população de cor, neste Estado, com o fim de lançar bases para sua solução”. A reunião seria realizada na sede da Legião Negra do Brasil (p. 1). Carta de Oracy Nogueira a Orlando Barbosa, 25/10/1950, 1p., Fundo Oracy Nogueira/ DAD/COC/Fiocruz. 
(Congresso Internacional de Relações de Raça) que discutisse a adoção de medidas para combatê-lo. O TEN tinha experiência em contatos com agências multilaterais (ONU) e intercâmbios com instituições, intelectuais e ativistas norte-americanos, franceses e africanos. Um segundo aspecto guarda relação com a recusa à participação em pesquisas de ordem acadêmica como a que fundamentava a proposta da UNESCO. Essa posição estava embasada em críticas aos "estudos afro-brasileiros" que remontavam aos anos 1930 e se referia ao negro como ser estático, enredado na tradição, no passado, em sua suposta condição de ser exótico, no momento em que o processo de modernização exigia uma análise sociológica do novo perfil, urbano, de negros e mulatos. O terceiro ponto está associado às propostas de atividades sugeridas à UNESCO, calcadas nas experiências culturais e intelectuais do TEN (sociodrama, psicodrama, etc.), conduzidas por Guerreiro Ramos, fruto do diálogo entre a sociologia e a psicologia social na busca pela elevação da autoestima, da valorização estética dos negros.

A despeito da derrota da proposta de Guerreiro Ramos, ela teve efeitos ao apontar a dimensão política da proposta da UNESCO, assim como a necessidade de diversificação do plano original. Desse modo, o desenvolvimento do projeto indicou a possibilidade de realização de um leque de pesquisas que surgiram a partir do conhecimento prévio de cientistas sociais da agência internacional, ampliado pelos contatos e sugestões de pesquisadores nacionais e estrangeiros com experiências diversas de ensino e pesquisa no Brasil e, por fim, como se verifica no Congresso do TEN, pela competição quanto à natureza do programa da UNESCO.

Guerreiro Ramos acreditava que o "problema do negro" não seria resolvido caso medidas tópicas não viessem acompanhadas por transformações estruturais. Quando da aprovação da lei Afonso Arinos em 1951, Guerreiro comentou, em tom irônico: "A chamada lei Afonso Arinos me parece útil como uma espécie de escarmento, embora o problema do negro [...] esteja reclaman- do medidas políticas e sociais, de caráter mais prático e menos abstrato. [...] Assim, acho útil a lei. É uma providenciazinha mais eficaz do que uma monografia folclórica”. ${ }^{18}$

O sintético e irônico comentário acerca dos limites da Lei Arinos, encerrando a oposição entre ações políticas e medidas de ordem mais abstrata, acadêmica, tem uma linha de continuidade com as críticas de Guerreiro às ciências sociais em processo de institucionalização e, mais especificamente, à abordagem antropológica do negro brasileiro, pensado exclusivamente como objeto de estudo, "monografia folclórica”, e não a partir do imperativo da transformação de suas condições de vida. Para a condução desse processo de mudança, Guerreiro Ramos compreende a necessidade de criação de uma elite negra, de uma intelligentsia, que tivesse por missão, junto com intelectuais brancos, a formulação de uma política de enfrentamento do racismo.

Recebido para publicação em 20 de setembro de 2014 Aceito em 11 de dezembro de 2014

\section{REFERÊNCIAS}

ALVES, Luiz. Para onde vai a afrologia? Clarim $d a$ Alvorada, $3^{\text {a }}$ Fase, n. 1, p. 1-2, 28/09/1940.

BASTIDE, Roger; FERNANDES, Florestan. O Preconceito Racial em São Paulo (projeto de estudo), Instituto de Administração da Faculdade de Ciências Econômicas e Administrativas da Universidade de São Paulo, 1951. n.118. $\overline{08 / 02 / 19} \cdot 5$.

Sugestões e Proposições. O Estado de São Paulo,

BICUDO, Virgínia Leone. Atitudes raciais de pretos e mulatos em São Paulo. São Paulo: Ed. Sociologia e Política, 2010.

CARNEIRO, Édison; FERRAZ, Aydano do Couto. O Negro no Brasil (Vários Autores). Rio de Janeiro: Civilização Brasileira, 1940, p. 7-11.

COSTA PINTO, Luiz de Aguiar. O negro no Rio de Janeiro: relações de raças numa sociedade em mudança. Rio de Janeiro: Editora UFRJ, 1998 [1953].

CONCURSOS da 'Rainha das Mulatas' e da 'Boneca de Pixe' Quilombo, n. 3, p. 12; n. 9, p. 6 -7, 1949.

GÓES, Fernando. Variações sobre o negro. v. 1, n. 4, s/p, 1939.

GUERREIRO RAMOS, A. Uma opinião: mais sociologia e

${ }^{18}$ Jornal de Letras, ano III, n. 26, ago. 1951, p. 15. 
menos política. A Manhã, 17/06, p. 3 e 6, 1945.

. Administração e política à luz da sociologia. Revista do Serviço Público. Rio de Janeiro, ano IX, v. 3, n. 1, p. 5-11, jul., 1946.

Notas sobre planificação social. Revista do Serviço Público, Rio de Janeiro, ano IX, v. 4, n. 3, p. 163-166, dez., 1946a. p. 8, 1948 .

Contatos raciais no Brasil. Quilombo, ano 1, no 1, $\overline{1948 a}^{\circ}$

Imigração e preconceito. A Manhã, 4/7/1948, p. 2,

Apresentação da Grupoterapia. Quilombo, ano II, n. 5, p. 6, junho,1949.

O negro no Brasil e um exame de consciência. Relações de Raça no Brasil. Rio de Janeiro, Edições Quilombo, p. 33-46,1950.

Os Estudos sobre o negro brasileiro. A Manhã, 10 de dezembro, p. 1-2, 1950 a.

. Narcisismo branco do negro brasileiro. A Manhã, 12 de novembro, p. 1 e 3, 1950 b.

Teoria e prática do psicodrama. Quilombo, v. 2, n. $\overline{6, \text { p. } 6}-7$, fev., 1950c.

Teoria e prática do sociodrama. Quilombo, v. 2, n

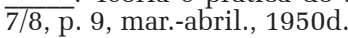

O Museu como sucedâneo da violência. Relações de Raça no Brasil. Rio de Janeiro: Edições Quilombo, p. 47-50, $1950 \mathrm{e}$.

A Unesco e as relações de raça. In: NASCIMENTO, A. Onegro revoltado, Rio de Janeiro: Nova Fronteira, 1982.

GRIN, M.; MAIO, M.C. $O$ antirracismo da ordem no pensamento de Afonso Arinos de Melo Franco, Topoi, v.14, n. 26, p. 33-45, 2013.

GUIMARÃES, Antonio Sergio; MACEDO, Márcio. Diário trabalhista e democracia racial negra dos anos 1940. Dados - Revista de Ciências Sociais, v. 51, nº1, p. 143-182, 2008.
HOLANDA, Sérgio Buarque de. Brancos e negros. In: Cobra de Vidro. São Paulo: Editora Perspectiva, 1978 .

INSTITUTO NACIONAL DO NEGRO. Quilombo, n. 3, p.11, 1949.

MACEDO, M. Abdias do Nascimento: a trajetória de um negro revoltado. Dissertação de Mestrado, Departamento de Sociologia, FFCL-USP, 283 p., 2005.

MAIO, M.C. O Contraponto Paulista: Florestan Fernandes, Oracy Nogueira e o Projeto Unesco de Relações Raciais. Antíteses, v. 7, n. 13, p. 10-39, 2014.

M.C. O projeto Unesco e a agenda das Ciências Sociais no Brasil dos anos 40 e 50. Revista Brasileira de Ciências Sociais, v. 14, n. 41, p. 141-158, 1999.

Uma polêmica esquecida: Costa Pinto, Guerreiro $\overline{R a m o s}$ e o tema das relações raciais. Dados - Revista de Ciências Sociais, v. 40, nº 1, p. 127-162, 1997.

MULLER, R.G. Identidade e cidadania: o teatro experimental do negro. Dionysios, n. 28, p. 11-13, 1945.

NASCIMENTO, Abdias, O senador Hamilton Nogueira denunciou a Constituinte uma fraude contra o negro: o professor Guerreiro Ramos aborda o importante problema. Diário Trabalhista, 24 de março, p. 6, 1946.

Espírito e fisionomia do teatro experimental do negro. Quilombo, v. 1, n. 3, p. 11, junho, , 1949.

. O $1^{\circ}$ Congresso do Negro Brasileiro. Quilombo, v. 2, n. 5, jan., p. 1, 1950.

O negro revoltado. Rio de Janeiro: Editora Nova Fronteira, 2a edição, 1982.

PIERSON, Donald. Brancos e pretos na Bahia: estudo de contato racial. São Paulo: Companhia Editora Nacional, 1945.

WERNECK VIANNA, Luiz. Revolução passiva: iberismo e americanismo no Brasil. Rio de Janeiro: Revan, 1997. 


\section{GUERREIRO RAMOS CHALLENGES UNESCO: social sciences, activism, and anti-racism}

Marcos Chor Maio

The article analyzes Guerreiro Ramos' criticisms of the UNESCO proposal to promote a series of studies on race relations in Brazil in the early 1950s. Focusing on the scholar's work from 1946 to 1950, the article explores his criticism of the tradition of African-Brazilian studies, his approaches to color prejudice from the perspective of the intersection of sociology with social psychology, and his thoughts on the need to forge a black intelligentsia in order to combat racial discrimination in Brazil. Although Guerreiro Ramos' proposal to replace the UNESCO academic research agenda with an International Conference on Race was not embraced, the idea had the unexpected effect of contributing to the expansion and diversification of UNESCO studies. The latter changes were facilitated by an openended scenario made possible by the autonomous work of a Transatlantic network of progressive social scientists who had diverse experiences in teaching and/or research in Brazil and who were sensitive to the demands presented at the First Brazilian Black Congress, sponsored by the Black Experimental Theater (TEN).

KEYwORDS: Anti-racism. Alberto Guerreiro Ramos. Black Experimental Theater. Social thought in Brazil. History of social sciences. UNESCO.
GUERREIRO RAMOS INTERPELLE L'UNESCO: sciences sociales, militance et antiracisme

Marcos Chor Maio

L'objectif de cet article est d'analyser les critiques que Guerreiro Ramos a faites à la proposition de l'UNESCO de promouvoir toute une série de recherches sur les relations raciales au Brésil au début des années 50. Létude analyse les travaux de Guerreiro Ramos de 1946 à 1950 en prenant en considération les critiques faites à la tradition des études afro-brésiliennes, les intersections entre la sociologie et la psychologie sociale et les réflexions du chercheur en sciences sociales sur le besoin de créer une intelligentsia noire en vue de combattre la discrimination raciale dans le pays. Bien que la proposition de Guerreiro Ramos de former un Congrès Internationale sur les Races, au lieu d'une recherche universitaire, n'aie pas abouti, elle a eu un effet non escompté avec l'augmentation et la diversification des études de l'UNESCO. L'avènement de tels changements s'est produit grâce à l'existence d'un scénario ouvert construit peu à peu à partir de l'action autonome de tout un réseau transatlantique de scientifiques sociaux progressistes ayant des expériences diverses d'enseignement et/ou de recherche au Brésil et qui ont été sensibles aux demandes présentées lors du Premier Congrès Noir Brésilien.

Mots-clés: Racisme. Théâtre Expérimental du Noir. Alberto Guerreiro Ramos. Pensée sociale au Brésil. Histoire des sciences sociales. UNESCO.

Marcos Chor Maio - Doutor em Ciência Política. Professor do Programa de Pós-graduação em História das Ciências e da Saúde da Casa de Oswaldo Cruz, PPGHCS/COC/Fiocruz. Pesquisador da Casa de Oswaldo Cruz/Fundação Oswaldo Cruz. Bolsista de Produtividade em Pesquisa do CNPq 1B. Suas áreas de pesquisa e ensino são: História das Ciências Sociais no Brasil; Raça, Ciência e Saúde no Pensamento Social Brasileiro; Organizações Internacionais e Políticas Nacionais. Atualmente desenvolve pesquisas que versam sobre ciências sociais, estudos de comunidade e saúde no Brasil; interfaces entre sociologia, antropologia e psicologia social nos estudos sobre raça e racismo no Brasil; políticas sociais com recorte racial no campo da saúde pública no Brasil. Publicações recentes: Health at the dawn of development: the thought of Abraham Horwitz. História, Ciências, Saúde-Manguinhos (Impresso), v. 22, p. 69-93, 2015; O contraponto paulista: Florestan Fernandes, Oracy Nogueira e o Projeto Unesco de relações raciais. Antíteses (Londrina), v. 7, n. 13, p. 10-39, 2014; Sob o signo do Acordos de Oslo: perspectivas diversas sobre o conflito israelo-palestino. História (São Paulo. Online), v. 33, p. 3-13, 2014. Donald Pierson e o Projeto do Vale do Rio São Francisco: cientistas sociais em ação na era do desenvolvimento. Dados, v. 56, n. 2, p. 245-284, 2013. 
